\title{
Shopping for Direct-to-Consumer Screening: Buyers and Clinicians Beware
}

\author{
Blake Charlton, MD and Rita F. Redberg, MD, MSC \\ Department of Internal Medicine, University of California San Francisco, San Francisco, CA, USA.
}

J Gen Intern Med 30(10):1400-1

DOI: $10.1007 / \mathrm{s} 11606-015-3313-7$

(c) Society of General Internal Medicine 2015

$\mathrm{H}$ ow often do clinicians help patients shop for screening tests? Probably rarely, if at all, but that will have to change if current corporate ventures into direct-to-consumer (DTC) medical screening continue.

Consider the case of HealthFair, a Florida-based company that sells DTC screening via a nationwide fleet of buses converted into laboratories. The company advertises a "Basic Package" including an electrocardiogram, carotid ultrasound, abdominal aortic ultrasound, and echocardiogram for \$179. A "Men's Package" adds testosterone and PSA levels, while a "Women's Package" adds CRP and TSH levels, each for a total of $\$ 347$. HealthFair's website identifies screening candidates as "over the age of 50 , or over 40 with additional risk factors." It shares results with local medical centers sponsoring screening events, and reports screening "over 1,000,000 individuals" since its founding in 1998. Assuming stable pricing, that translates to total revenue of $\$ 179$ to $\$ 347$ million. HealthFair reports having gathered "millions of data points" that reveal an "alarming rate of undetected subclinical atherosclerotic disease." However, we could find no published data regarding benefits, harms, or costs for HealthFair-screened patients. And HealthFair is not the only or even the largest DTC screening corporation; Life Line Screening - an Ohiobased corporation that partners with hospitals and community groups - claims on its website to have screened eight million people since its inception in 1993.

Any screening test exposes patients to the risk of further testing, overdiagnosis, anxiety, cost, and exposure to contrast and radiation. This risk is justified for tests that have evidence of benefit, such as colorectal cancer screening for adults over 50. Tests without evidence of benefit should be regarded with an abundance of caution, if not skepticism. As inappropriate screening is becoming more common, its hazards have become topics in medical school curricula and on licensing exams. Some posit that it is unethical to sell DTC screening without proven benefit. ${ }^{2}$ Clinicians commonly explain to their patients why a given test may or may not be beneficial; however, they rarely discuss the possibility of purchasing a

Published online April 9, 2015 test directly in the marketplace. Yet clinician input would be invaluable to patients as they decide whether or not to purchase DTC screening products, especially as patients need clinical counsel to understand the implications of the test results.

Consider again HealthFair - their potential customers may be surprised to learn that screening adults over 50 (or over 40 years with risk factors) with electrocardiography, carotid ultrasound, abdominal aortic ultrasound, echocardiography, PSA, or CRP runs counter to recommendations from the American College of Cardiology, the American Society of Echocardiography, and the U.S. Preventive Services Task Force (USPSTF). Interestingly, none of these groups objected to HealthFair's practices. It was Public Citizen, a consumers' rights group, who last June sent letters to 20 hospitals urging them to break with HealthFair because their screening practices were "more likely to cause harm than to provide benefit."

HealthFair responded, restating confidence in their "program to educate the consumer, pre-select those that are candidates for screenings, and provide them with the choice to obtain testing." They defended their partnerships with hospitals as an "avenue" through which patients might "have their results reviewed and discussed with qualified healthcare providers. This puts healthcare decisions in the hands of consumers and their providers, not in the hands of government." The claim to empower clinicians is unfounded, given that HealthFair sells tests without the benefit of a primary care provider's input as to whether the test should be performed at all. And the claim to be fending off government interference is a curious one, as only clinicians and their patients decide if a test will be performed. Private insurance companies and government-sponsored insurers, such as Medicare and Medicaid, decide if and how much to reimburse for such tests.

Public Citizen urged the Joint Commission to deny HealthFair accreditation and suspend accreditation for their partners. ${ }^{3}$ More recently, Wallace and colleagues have called for hospitals associated with DTC screening companies either to provide more evidence for their screening practices and more transparency regarding their relationships or to end their associations. ${ }^{4}$ Under the resulting media scrutiny, HealthFair's chief executive, Mr. Terry Diaz, stated, "We agree there's no proof a life is in fact saved." He also admitted that "We took some liberties in the advertising." 5

Underlying this dust-up is the question of who can best make decisions about screening. Giving the choice to patients 
would maximize personal freedom; however, it exposes patients to potentially unneeded medical interventions, and therefore harm, worry, radiation, contrast, and cost, without known benefit. Clinicians are better positioned to evaluate the risks and benefits of screening.

The issues raised by HealthFair's buses are not new. In 2013, 23 andMe was providing DTC genetics tests, many without proven clinical significance. A confrontation between the FDA and 23andMe sparked debate about medical paternalism, individuals' right to purchase genetic information, and concerns about the validity of the information for sale. The FDA restricted 23andMe to genealogy testing, but there are myriad other companies venturing into DTC screening, particularly those specializing in mobile technology. Today shoppers can transform their mobile phones into diagnostic tools ranging from a single-lead EKG to a glucometer. Ambitious software developers hope to use mobile phones to diagnose everything from COPD to Parkinson's disease. The much-hallowed Theranos corporation is promising an array of laboratory tests from a few drops of fingerstick blood, which could transform the DTC market. Given technology's rapid advancement, commercially available self-administered screening will surely increase.

Worse, high-deductible insurance plans may inappropriately accelerate the spread of DTC screening. With a yearly deductible of $\$ 500$, patients looking to cut costs might forgo seeing their primary clinicians and choose instead to purchase HealthFair's "Basic Package" for \$175-likely without consideration for the costs of additional testing and clinical follow-up that potentially inappropriate DTC screening might trigger. Alternately, a wheezing patient might prefer to use a not-yetvalidated mobile phone app for $\$ 2.99$ that promises to estimate pulmonary function from the sound of the patient blowing across the microphone instead of the physician-ordered pulmonary function test. For these reasons, high-deductible plans may motivate patients to seek seemingly cheaper but potentially harmful forms of screening of unknown quality.

Part of the solution must come from education and regulation. Companies selling DTC screening should have to inform potential consumers that the Affordable Care Act (ACA) already mandates that patients may not be charged out-of-pocket for any screening test rated Grade A or B by the USPSTF. Clinicians should mention this aspect of the ACA to patients when discussing screening in order to thwart the notion that a high premium makes DTC screening a safe and more affordable option. Companies selling DTC screening should be required to inform consumers about the risks of screening and professional society recommendations regarding the testing.

The most important solutions to the problems posed by DTC screening must come from patient and clinician discussion as well as stricter oversight of DTC advertisements with false or misleading health claims. New technological and entrepreneurial innovations will periodically allow, or even encourage, patients to purchase potentially inappropriate screening. That is why it will become increasingly important for patients and clinicians to discuss the evolving evidence, risks, benefits, and costs associated with DTC screening. To keep their patients safe, primary care providers will have to help patients decided when, if ever, to shop for screening.

\section{Acknowledgements: None \\ Funding Sources: None \\ Conflict of interest: The authors declare that they do not have a conflict.}

Corresponding Author: Blake Charlton, MD; Department of Internal Medicine, University of California San Francisco, 505 Parnassus Ave., San Francisco, CA 94143, USA (e-mail: blake.charlton@ucsf.edu).

\section{REFERENCES}

1. HealthFair website. http://healthfair.com/ Accessed 17 March 2015.

2. Wallace EA, Schumann JH, Weinberger SE. Ethics of commercial screening tests. Ann Intern Med. 2012;157(10):747-8.

3. Public Citizen website. http://www.citizen.org/ Accessed 17 March 2015.

4. Wallace EA, Schumann JH, Weinberger SE. Hospital relationships with direct-to-consumer screening companies. JAMA. 2014;312(9):891-2.

5. Cincinnati Business Courier. http://www.bizjournals.com/cincinnati/ news/2014/09/09/exclusive-mercy-health-partner-welcomes-review-of. html Accessed 17 March 2015. 